\title{
Methane formation in faunated and ciliate-free cattle and its relationship with rumen volatile fatty acid proportions
}

\author{
By F. G. WHITELAW, J. MARGARET EADIE, L. A. BRUCE \\ AND W. J.SHAND \\ Rowett Research Institute, Bucksburn, Aberdeen AB2 9SB
}

\section{(Received 21 September 1983 - Accepted 23 March 1984)}

\begin{abstract}
1. Twelve steers fitted with rumen cannulas were used in three separate experiments to investigate the effects of the presence or absence of rumen ciliate protozoa on methane production. The diet consisted of $850 \mathrm{~g}$ barley and $150 \mathrm{~g}$ protein supplement $/ \mathrm{kg}$, and was given in three feeds daily at a restricted level of $61 \mathrm{~g} / \mathrm{kg} \mathrm{live} \mathrm{weight}{ }^{0 \cdot 75}$. Animals were defaunated initially by allowing ad lib. consumption of this diet and were then maintained ciliate-free by isolation or were faunated by inoculation with a mixed ciliate suspension. Samples of rumen fluid were taken routinely for the assessment of microbial populations and for volatile fatty acid (VFA) analysis and energy and nitrogen balances and digestibility measurements were made at intervals while animals were confined in respiration
\end{abstract} chambers.

2. In each experiment the rumen VFA proportions changed from a high-propionate pattern under ciliate-free conditions to a low-propionate, high-butyrate pattern in the presence of ciliates: differences between treatments were highly significant $(P<0.001)$. There were also marked differences between treatments in $\mathrm{CH}_{4}$ production but a reliable comparison was possible only in Expt 3, in which $\mathrm{CH}_{4}$ was significantly higher $(P<0 \cdot 001)$ in the presence of a rumen ciliate population. In Expt 3 the increased loss of energy as $\mathrm{CH}_{4}$ in the faunated animals amounted to $4.8 \mathrm{MJ} / 100 \mathrm{MJ}$ energy intake.

3. Stoichiometric estimates of $\mathrm{CH}_{4}$ production derived from the observed VFA proportions showed good agreement with $\mathrm{CH}_{4}$ production as measured in respiration chambers. On average, the stoichiometric $\mathrm{CH}_{4}$ values overestimated $\mathrm{CH}_{4}$ production by a factor of 1.08 .

4. Highly significant linear relationships $(P<0.001)$ were observed between the molar proportion of each major VFA and the quantity of $\mathrm{CH}_{4}$ produced: the proportion of propionic acid was inversely related to $\mathrm{CH}_{4}$ and showed the lowest residual standard deviation of all the relationships examined.

5. The losses of energy in faeces and urine did not differ between treatments hence the increased loss of energy as $\mathrm{CH}_{4}$ in the faunated animals resulted in a significant reduction in the metabolizability of the diet from 0.73 to $0.69(P<0.05)$. No significant differences were detected between treatments in heat production, apparent digestibility coefficients or $\mathrm{N}$ balance.

6. It is suggested that the rumen ciliates, by modifying the rumen VFA proportions, are directly responsible for the increased $\mathrm{CH}_{4}$ production in faunated animals.

Previous work in this laboratory has shown that rumen ciliate protozoa are normally absent from cattle given $a d$ lib. access to an all-concentrate diet but can be established in large numbers when the same diet is given in amounts below appetite (Eadie et al. 1970). When intake is restricted and the daily allowance is offered in three equal meals the presence of ciliates gives rise to marked changes in the pattern of rumen fermentation. In particular, rumen $\mathrm{pH}$ is higher and the volatile fatty acids (VFA) in rumen fluid show a lower proportion of propionic acid and a much higher proportion of butyric acid than is encountered when the diet is offered ad lib. (Eadie et al. 1970; Whitelaw et al. 1972). In contrast, restriction of intake in ciliate-free animals results in rumen VFA mixtures with a high proportion of propionic acid, similar to those observed under ad lib. conditions (Whitelaw et al. 1972). In vitro incubations of whole rumen contents have also indicated a lower rate of VFA production in faunated than in ciliate-free animals (Whitelaw et al. 1970) and it has been suggested that many of the effects of ciliates on this feeding regimen can be explained by reference to their ability to ingest and store dietary starch. Ingestion of starch by the ciliates, particularly if present in large numbers, would have the effect of rendering a large proportion of this substrate unavailable to bacterial attack in the immediate post-feeding period. 
Another way in which the presence of an active ciliate population might influence the nature of the end-products in the rumen is in relation to methane production. The formation of both acetic and butyric acids is accompanied by the production of hydrogen whereas propionic acid production involves a net uptake of $\mathrm{H}_{2}$ (see Czerkawski, 1969). The relative rates of formation of these three acids thus largely determine the amount of excess $\mathrm{H}_{2}$ available in the rumen and ultimately converted to $\mathrm{CH}_{4}$ by the methanogenic bacteria. On theoretical grounds, therefore, the differing proportions of VFA observed under ciliate-free and faunated conditions in these cattle would be expected to result in quite large differences in the quantity of $\mathrm{CH}_{4}$ produced. Stoichiometric calculations using the equations of Ørskov et al. (1968) and based on the typical VFA proportions observed in the two situations indicate that $\mathrm{CH}_{4}$ formation in faunated animals might be increased by a factor of two over their ciliate-free counterparts.

The experiments described in the present paper were designed first to examine the hypothesis, derived from stoichiometric theory, that the presence of ciliates results in an increase in $\mathrm{CH}_{4}$ production and secondly to investigate the relationships which exist between rumen VFA proportions and $\mathrm{CH}_{4}$ production. The experiments were conducted in respiration chambers and the opportunity was taken to measure energy and nitrogen balances under the two microbial situations. A brief account of these experiments has been published elsewhere (Whitelaw et al. 1983).

\section{MATERIALS AND METHODS}

Animals and diet. Twelve Friesian steers were used in groups of four in three separate experiments. The mean initial live weights were 278, 260 and $217 \mathrm{~kg}$ in Expts 1, 2 and 3 respectively and each steer had been fitted with a cannula in the rumen under general anaesthesia 8-12 weeks before the start of the experiments (McKenzie \& Kay, 1968).

The diet consisted of a pelleted concentrate mixture containing $850 \mathrm{~g}$ barley and $150 \mathrm{~g}$ protein-mineral-vitamin supplement $/ \mathrm{kg}$ in which the protein was supplied as a $2: 1(\mathrm{w} / \mathrm{w})$ mixture of soya-bean meal and fish meal (Preston, 1963). The total $\mathbf{N}$ content of the diet varied between 26.4 and $27.9 \mathrm{~g} / \mathrm{kg}$ dry matter (DM) in different batches and different experiments. Apart from short periods when the diet was offered ad lib. (see below) the daily intake of air-dry feed $\left(870 \mathrm{~g} \mathrm{DM} / \mathrm{kg}\right.$ ) was kept constant at $61 \mathrm{~g} / \mathrm{kg}$ live weight ${ }^{0.75}$, adjusted weekly according to individual live weight and given as three equal meals at $08.00,14.00$ and 20.00 hours. This restricted level of intake was considered to be about $70 \%$ of maximal intake and was fractionally less than the level of $70 \mathrm{~g} / \mathrm{kg}$ live weight ${ }^{0.73}$ which had been found to support large populations of rumen ciliates in previous studies (Whitelaw et al. 1972).

Plan of experiments. The three experiments were carried out during consecutive 8-month periods. In each experiment four animals were given the barley diet ad lib. for a period of at least 5 weeks to ensure the removal of ciliate protozoa from the rumen and this was followed by an initial period of 3 weeks at the restricted level of intake. In Expt 1, two animals were then inoculated with a mixed ciliate population and the other two were kept ciliate-free by isolation in individual, totally enclosed pens. Measurements of gaseous exchange and of energy and $\mathrm{N}$ balance were made in the respiration chambers on two occasions in each animal at approximately 4-week intervals. All four animals were then given ad lib. intake for 3 weeks and restricted intake for 2 weeks after which the faunated and ciliate-free treatments were reversed and the measurements repeated. The procedure for Expts 2 and 3 was essentially similar to that of Expt 1, except that all four animals were maintained in the ciliate-free state in the first phase of the experiment and all were inoculated with ciliates in the second phase. This change was introduced because the periods of total 
isolation in Expt 1 had been found to make the animals intractable and difficult to handle. In these later experiments all animals were housed together in open, individual pens in contact with one another but out of contact with all other ruminants.

Calorimetric measurements and energy and $N$ balance. Measurements of oxygen consumption and of carbon dioxide and $\mathrm{CH}_{4}$ production were made in the automated confinement respiration chambers described by Blaxter et al. (1972). While in the respiration chambers animals were equipped with harnesses for the separate collection of faeces and urine (Webster et al. 1974); in Expts 1 and 3 these collections were made over $6 \mathrm{~d}$ and the measurements of respiratory exchange were made over the final $4 \mathrm{~d}$. In Expt $2, \mathrm{CH}_{4}$ production alone was measured in the respiration chambers over 3-d periods and 6-d collections of faeces and urine were made on separate occasions. Heat production in Expts 1 and 3 was calculated from the gaseous exchange and the urinary $\mathrm{N}$ excretion using the factors proposed by Brouwer (1965).

The calibration of the infra-red $\mathrm{CH}_{4}$ and $\mathrm{CO}_{2}$ analysers and the paramagnetic $\mathrm{O}_{2}$ analyser associated with the respiration chamber was as described by Blaxter et al. (1972) except that the composition of the gas mixture used as the daily reference standard ('span' gas) was determined by passage through a similar set of analysers attached to an open-circuit respiration calorimeter (Pullar, 1969). These analysers, in turn, were calibrated at intervals by the gravimetric procedures described by Brockway et al. (1971).

Rumen ciliate inoculations. Inocula of mixed rumen ciliates were prepared as described by Whitelaw et al. (1972) from the rumen fluid of a cow given a mixed roughage-concentrate diet. The ciliates present in the inocula were Entodinium spp., Enopoplastron triloricatum, Eremoplastron spp., Epidinium spp., Eudiplodinium maggii, Ostracodinium spp., Isotricha spp. and Dasytricha ruminantium. The inoculations were routinely given on two occasions with an interval of 1 week but in some instances further inoculations were required in certain animals to establish an adequate ciliate population.

Rumen samples. Samples of rumen fluid for ciliate examination and for $\mathrm{pH}$ and VFA measurements were obtained twice weekly at 11.00 hours from each animal throughout the experiment and at more frequent intervals, often daily, while the animals were held in the respiration chambers. Samples were obtained via the rumen cannula by gentle suction. Previous experiments in which the same feeding schedule was employed had shown that rumen VFA proportions showed only minor changes throughout a $24 \mathrm{~h}$ period and that samples taken at 11.00 hours were representative of the daily VFA pattern (Whitelaw et al. 1972). Wet preparations of all samples were examined to assess the nature of the ciliate population or to establish, where relevant, that the animals were ciliate-free. No counts were made of the total number of ciliates since previous experience had shown that such counts are of limited value in situations where the organisms present differ greatly in size (e.g. Epidinium spp. and Entodinium spp.) and the proportions of each in the population can vary over a wide range (Eadie et al. 1970). An arbitrary scoring system based on visual appraisal by an experienced protozoologist (J.M.E.) was used throughout to assess the size of the ciliate populations. Rumen fluid samples preserved with an equal volume of formalin $(40 \mathrm{~g} / \mathrm{l})$ were kept for later comparisons of microbial populations. Gram films were also examined from each sample and assessments of the bacterial types obtained in culture and total viable counts were made at intervals using the starch medium of Kurihara et al. (1968).

Stoichiometric calculations. In the application of stoichiometric principles to the rumen fermentation the assumption is made that the proportions of VFA in rumen fluid represent the relative rates of production of individual acids within the rumen (Wolin, 1960; Ørskov et al. 1968). Measurements of VFA production rates in cattle given restricted amounts of a barley diet have shown this to be a valid assumption for this dietary regimen (Whitelaw et al. 1970). Formulas based on those of Ørskov et al. (1968) were used to calculate the 
theoretical amounts of $\mathrm{CH}_{4}$ produced by each animal at the time of each respiration chamber measurement. Whereas Ørskov et al. (1968) calculated $\mathrm{CH}_{4}$ production on the basis of acetic, propionic and butyric acids only, an attempt was made in the present work to take account also of the valeric and caproic acid produced. This was done arbitrarily by dividing by two the percentage of 'other acids' present (which included the branched-chain $\mathrm{C}_{4}$ - and $\mathrm{C}_{5}$-isomers) and treating this portion as propionate in the calculations. $\mathrm{CH}_{4}$ energy as a percentage of the gross energy intake was calculated as

which condenses to

$$
0.314 \mathrm{~F}\left(\frac{0.5 p a-0.25(p p+0.5 p o)+0.5 p b}{0.5 p a+0.5(p p+0.5 p o)+p b}\right),
$$

$$
0.314 \mathrm{~F}\left(\frac{2 p a-(p p+0.5 p o)+2 p b}{2 p a+2(p p+0.5 p o)+4 p b}\right),
$$

where 0.314 is the ratio, $\mathrm{CH}_{4}$ energy : hexose energy $(\mathrm{kJ} / \mathrm{mol})$ and $p a, p p, p b$ and $p o$ are the molar percentages of acetic, propionic, butyric and 'other acids' respectively: the main expression in parentheses thus represents $\mathrm{mol} \mathrm{CH}_{4}$ produced $/ \mathrm{mol}$ hexose intake. The factor $\mathrm{F}$ is the digestible carbohydrate content of the diet, considered as hexose with a molecular weight of 162 and an energy value of $2812 \mathrm{~kJ} / \mathrm{mol}$, and expressed as a percentage of the gross energy of the diet. In the present experiments the value of $\mathrm{F}$ was 61 , based on a carbohydrate content (crude fibre $+\mathrm{N}$-free extracts) of $751 \mathrm{~g} / \mathrm{kg}$, an apparent digestibility coefficient of $0 \cdot 84$, as observed for dietary energy, and a gross energy value of $18 \cdot 0 \mathrm{MJ} / \mathrm{kg}$ DM.

The values for $\mathrm{CH}_{4}$ obtained in these stoichiometric calculations are, of course, maximum values since they make the assumption that all dietary hexose is fermented to VFA and that all 'excess' metabolic $\mathrm{H}_{2}$ produced is utilized in the reduction of $\mathrm{CO}_{2}$ to $\mathrm{CH}_{4}$ (Ørskov et al. 1968).

Analytical methods. The DM of feeds and faeces samples were determined by drying to constant weight at $105^{\circ}$ in a forced-air oven. Gross energies of feeds, faeces and urine were determined by bomb calorimetry and total $\mathrm{N}$ by an automated Kjeldahl procedure (Davidson et al. 1970). The $\mathrm{C}_{2}-\mathrm{C}_{6}$ VFA in rumen fluid including the branched-chain isomers were separated by gas-liquid chromatography (Fell et al. 1968). The $\mathrm{CH}_{4}$ content of reference gas samples and of chamber air during the recalibration of the analysers in Expt 2 was determined by gas-solid chromatography: molecular sieve 5A (80/100 mesh) was used as column packing and the response of the flame-ionization detector was related to that obtained with accurately standardized gas mixtures containing appropriate concentrations of $\mathrm{CH}_{4}$ (British Oxygen Co. Ltd, Deer Park Road, London).

Statistical methods. For most of the measurements examined the three experiments were combined and the within-animal mean values subjected to a two-way analysis of variance, allowing for non-orthogonality in the observations. However, in establishing relationships between $\mathrm{CH}_{4}$ and VFA proportions by regression analysis, each individual period of measurement in the respiration chambers was treated as an independent observation. This course was adopted because the rumen microbial populations on occasion differed slightly between replicate measurements within each treatment period and this could result in reciprocal changes in $\mathrm{CH}_{4}$ and VFA proportions. The regression relationships established in this way did not differ significantly from those based on within-animal mean values but were considered to be better indicators of the true underlying relationships. 


\section{RESULTS}

Rumen microbial populations. The scoring system adopted for the assessment of rumen ciliate populations was based on a concept developed by Eadie et al. (1970) which attempted to take account of ciliate volume as well as numbers. On visual appraisal most of the ciliate populations which developed in the present experiments fell within the approximate range $2.0-3.0 \times 10^{6}$ organisms $/ \mathrm{ml}$ and would normally be considered very large populations. In some animals the ciliate populations took longer to establish or showed fluctuation in number such that only moderate populations, more typical of roughage-fed animals, were seen on occasions (approximately $0.5-1.0 \times 10^{6}$ organisms $/ \mathrm{ml}$ ); in these cases respiration chamber measurements were either delayed until the situation improved or omitted completely. On other occasions, particularly in Expt 3, some animals which had failed to acquire a ciliate population by inoculation were used to obtain further measurements under ciliate-free conditions.

As in previous studies (Eadie et al. 1970; Whitelaw et al. 1972), members of the genera Entodinium, Epidinium and Eremoplastron were the only organisms to develop in significant numbers from the original inoculum. Isotricha spp. were occasionally present in small numbers.

The rumen bacterial populations seen in Gram films and in cultures were similar in most respects to that described previously (Eadie \& Mann, 1970; Whitelaw et al. 1972) with Bacteroides spp. being the predominant organism present under both ad lib. and restricted feeding regimens. There were no marked differences in bacterial types between faunated and ciliate-free animals but, as before, total bacterial numbers were reduced in the presence of a ciliate population (Eadie \& Mann, 1970).

Rumen VFA proportions and methane production. Mean values for the molar proportions of acetic, propionic, butyric and 'other' acids for each treatment group are given in Table 1 together with values for $\mathrm{CH}_{4}$ as measured in the respiration chamber or as derived by stoichiometric calculations from the rumen VFA values. In each experiment the VFA patterns showed the expected change from a high-propionate to a low-propionate, high-butyrate fermentation in changing from the ciliate-free to the faunated state. Differences between treatments in each of the three major acids were highly significant $(P<0.001)$ and this was true also of the 'other acids' fraction, which was consistently higher under ciliate-free conditions. Within this fraction the major differences between treatments tended to be in the proportions of $n$-valeric and caproic acids, rather than in the branched-chain acids.

The measured levels of $\mathrm{CH}_{4}$ production in Expt 1 showed the twofold difference between treatments which had been inferred from stoichiometric principles although the absolute values recorded exceeded by a considerable margin the calculated maximum yields of 6.67 and $12.06 \mathrm{MJ} / 100 \mathrm{MJ}$ intake for ciliate-free and faunated animals respectively (Table 1). In Expt 2 also, very high values for $\mathrm{CH}_{4}$ formation relative to the amounts calculated by stoichiometry were obtained for the ciliate-free animals examined in the first phase of the experiment (Expt 2a). These observations cast doubts on the accuracy of the infra-red $\mathrm{CH}_{4}$ analyser and a rigorous series of recovery tests at this point identified both a fault in the calibration procedures and an unsuspected non-linearity of response. The effect of these errors was such that $\mathrm{CH}_{4}$ concentrations were consistently overestimated but by variable amounts. The extent of overestimation could not be accurately determined retrospectively for individual periods of measurement but appeared on average to be about $40 \%$ for ciliate-free animals and $30 \%$ for faunated animals. Recalculation of the $\mathrm{CH}_{4}$ values for Expts 1 and $2 \mathrm{a}$ by the use of these approximate correction factors yielded values which agreed well with the corresponding stoichmetric values given in Table 1. In view of the empirical 


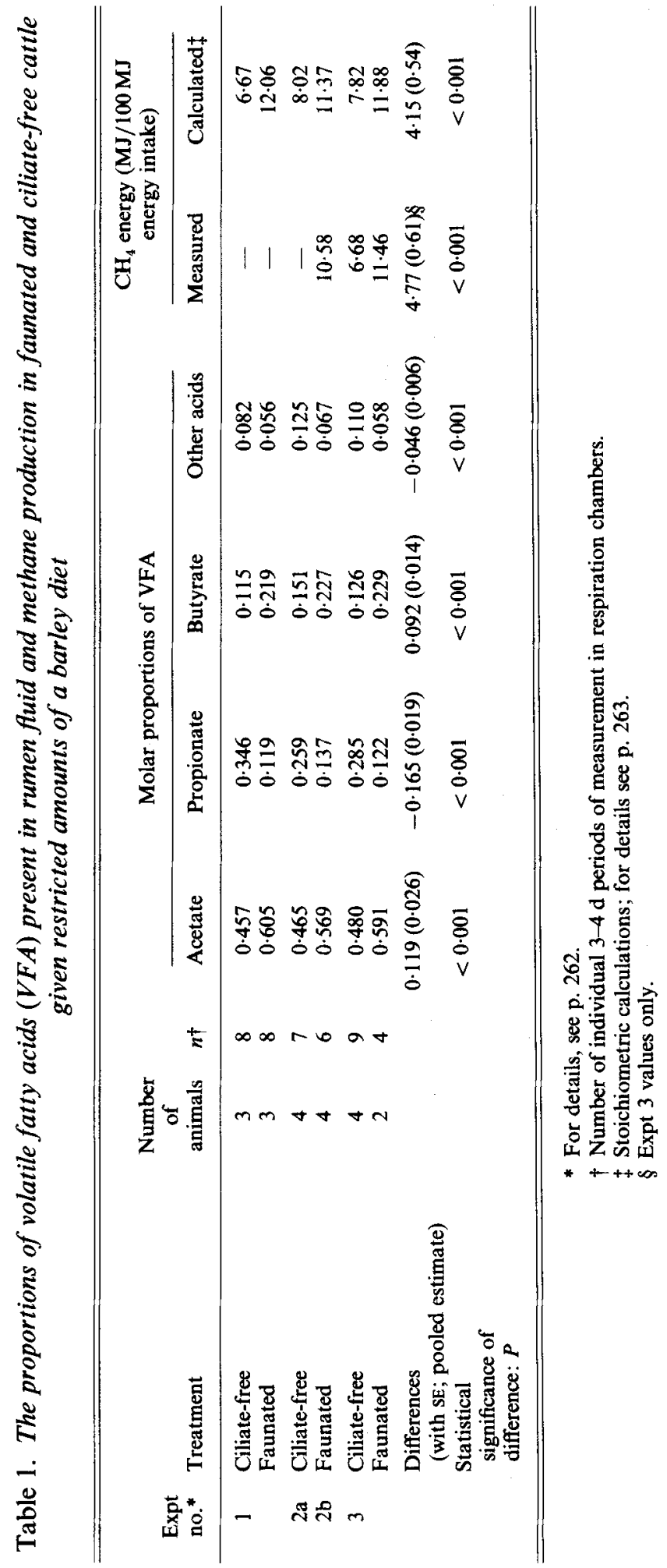




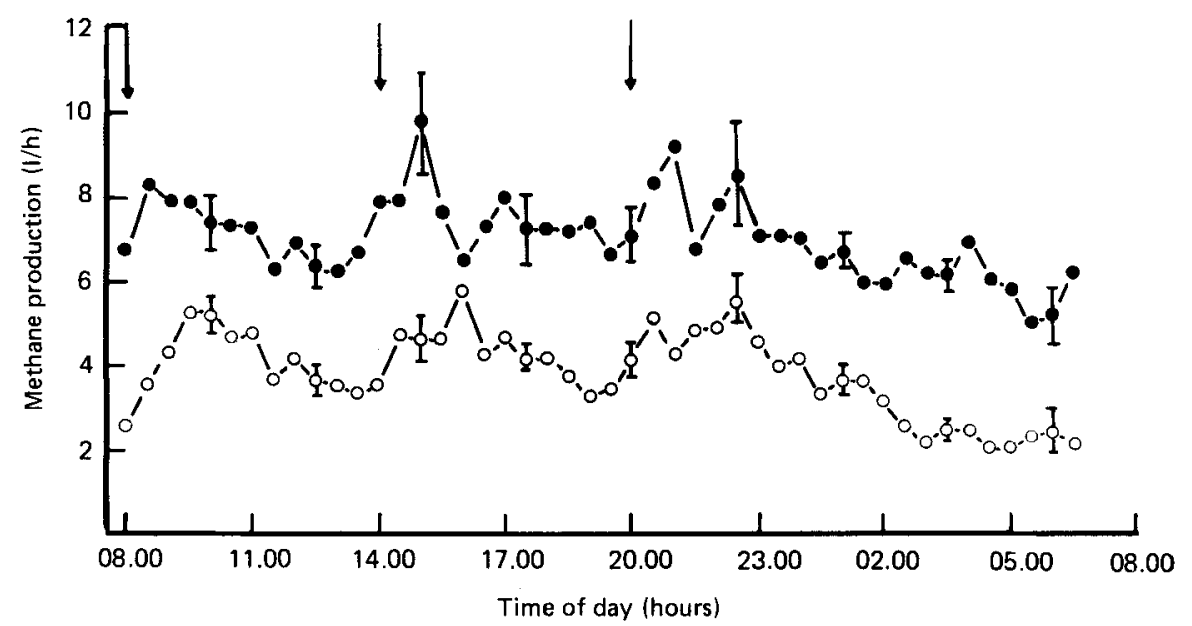

Fig. 1. The pattern of methane production throughout $24 \mathrm{~h}$ in faunated $(O)$ and ciliate-free $(O)$ cattle given restricted amounts of a barley diet. Each point represents the mean of sixteen observations, derived from four animals on each of four successive days, with their standard errors represented by vertical bars. $\downarrow$, Time of feeding.

nature of the corrections, however, these values have not been included in the tables nor in the statistical analyses.

Recalibration of the analyser by the use of carefully standardized gas mixtures resulted in measured values for $\mathrm{CH}_{4}$ production in the faunated animals of Expt $2 \mathrm{~b}$ which were consistent with the calculated values. In Expt 3, which was conducted principally to obtain additional values for ciliate-free animals, a highly significant difference in $\mathrm{CH}_{4}$ production was observed between the faunated and ciliate-free treatments $(P<0.001$, Table 1$)$. This difference represented an additional loss of energy by the faunated group amounting to $4.8 \%$ of the energy ingested and agreed well with the mean difference of $4.2 \%(P<0.001)$ which was obtained from the stoichiometric calculations relating to all three experiments (Table 1).

Examination of the respiration-chamber results for the successive $0.5 \mathrm{~h}$ periods of confinement on which daily measurements were based showed that the pattern of $\mathrm{CH}_{4}$ production over $24 \mathrm{~h}$ was similar for each treatment but was at a consistently higher level for the faunated animals. As shown in Fig. 1 both groups had a fairly constant rate of $\mathrm{CH}_{4}$ formation throughout the day with only relatively minor peaks of production being seen during the 2-h periods following each meal.

The regression of measured $\mathrm{CH}_{4}$ production on VFA proportions for the nineteen sets of observations obtained in Expts $2 b$ and 3 gave the relationships summarized in Table 2. The lowest residual standard deviations were for those relationships in which either propionic acid alone or a combined function involving all three major acids (Ørskov et al. 1968) was the independent variable: for each of these the error attached to predicted values of $\mathrm{CH}_{4}$ was approximately $1.06 \mathrm{MJ} / 100 \mathrm{MJ}$ intake or $12 \%$ of the mean amount of methane produced. Fig. 2 shows the relationship between measured $\mathrm{CH}_{4}$ and the molar proportion of propionic acid and illustrates also the clear distinction which exists between the values observed for the faunated and ciliate-free treatments. Essentially similar relationships but each having considerably lower error components were obtained between $\mathrm{CH}_{4}$ production calculated by stoichiometry and each of the listed VFA or VFA combinations: only the 


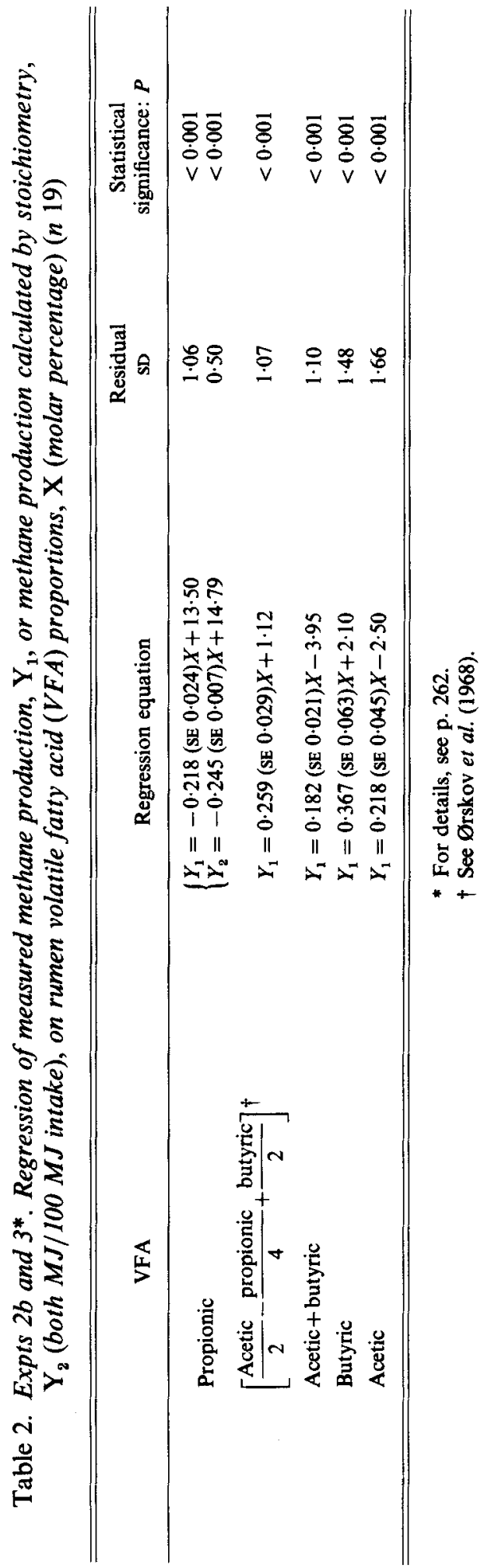




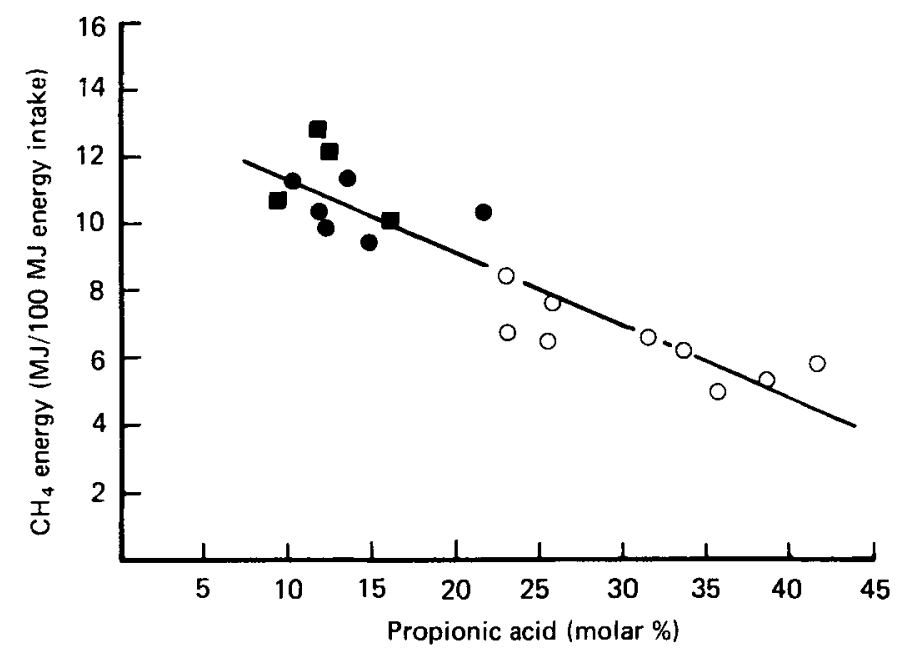

Fig. 2. The relationship between methane production ( $Y ; \mathrm{MJ} / 100 \mathrm{MJ}$ energy intake) and the molar percentage of propionic acid $(X)$ in the rumen fluid of faunated $((O)$, Expt $2 b ;(\square)$, Expt 3$)$ and ciliate-free ((O), Expt 3) cattle given restricted amounts of a barley diet. The regression equation was $Y=-0.218 X+13 \cdot 5(P<0 \cdot 001$, see Table 2$)$.

equation relating to the regression of 'stoichiometric $\mathrm{CH}_{4}$ ' on propionic acid is included in Table 2, since this had the lowest error (0.50 MJ or $5.3 \%$ of the mean) amongst the regressions in this group.

Energy metabolism. The mean intakes of DM and energy were lower for the ciliate-free than for the faunated groups in each experiment. In part, this reflected the fact that on average faunated animals were heavier at the time of the observations but even when expressed per unit metabolic body size ( $\mathrm{kg}$ live weight $\mathrm{t}^{0.75}$ ) there were significant differences in intake between treatments $(P<0.001$; Table 3$)$. The apparent digestibility coefficients for DM and energy did not differ significantly between treatment groups and the same was true of the proportionate losses of energy in faeces and urine. In consequence, the significant increase in the energy lost as $\mathrm{CH}_{4}$ in the faunated animals in Expt 3 was reflected in a significant reduction $(P<0.05)$ in the energy metabolized by this treatment group. The metabolizable energy (ME) of the barley diet was thus $13.05 \mathrm{MJ} / \mathrm{kg} \mathrm{DM}$ when given to the ciliate-free animals but only $12.44 \mathrm{MJ} / \mathrm{kg} \mathrm{DM}$ when given to faunated animals. A similar value, 12.51 , can be calculated from the values relating to the faunated animals in Expt 2.

In addition to the problems associated with the $\mathrm{CH}_{4}$ analysers, the measurements of respiratory exchange in these experiments were confounded by intermittent mechanical faults in the $\mathrm{O}_{2}$ and $\mathrm{CO}_{2}$ analysers. Reliable estimates of daily heat production were obtained in only sixteen individual periods of measurement in Expts 1 and 3 but these indicated that there were no significant differences in heat production between the faunated and ciliate-free groups (Table 3). Estimates of energy retention could be obtained only for Expt 3 and showed a difference in favour of the ciliate-free animals of 4.51 MJ/100 MJ intake which was consistent with the reduction in $\mathrm{CH}_{4}$ energy losses by this group: the variability in these esimates was high however and the difference failed to reach significance.

$N$ metabolism. The differences between treatment groups in daily DM intake reported previously resulted also in daily $\mathrm{N}$ intakes which tended to be higher for the faunated than for the ciliate-free groups (Table 4). Expressed per unit energy intake, the intakes of $\mathrm{N}$ 


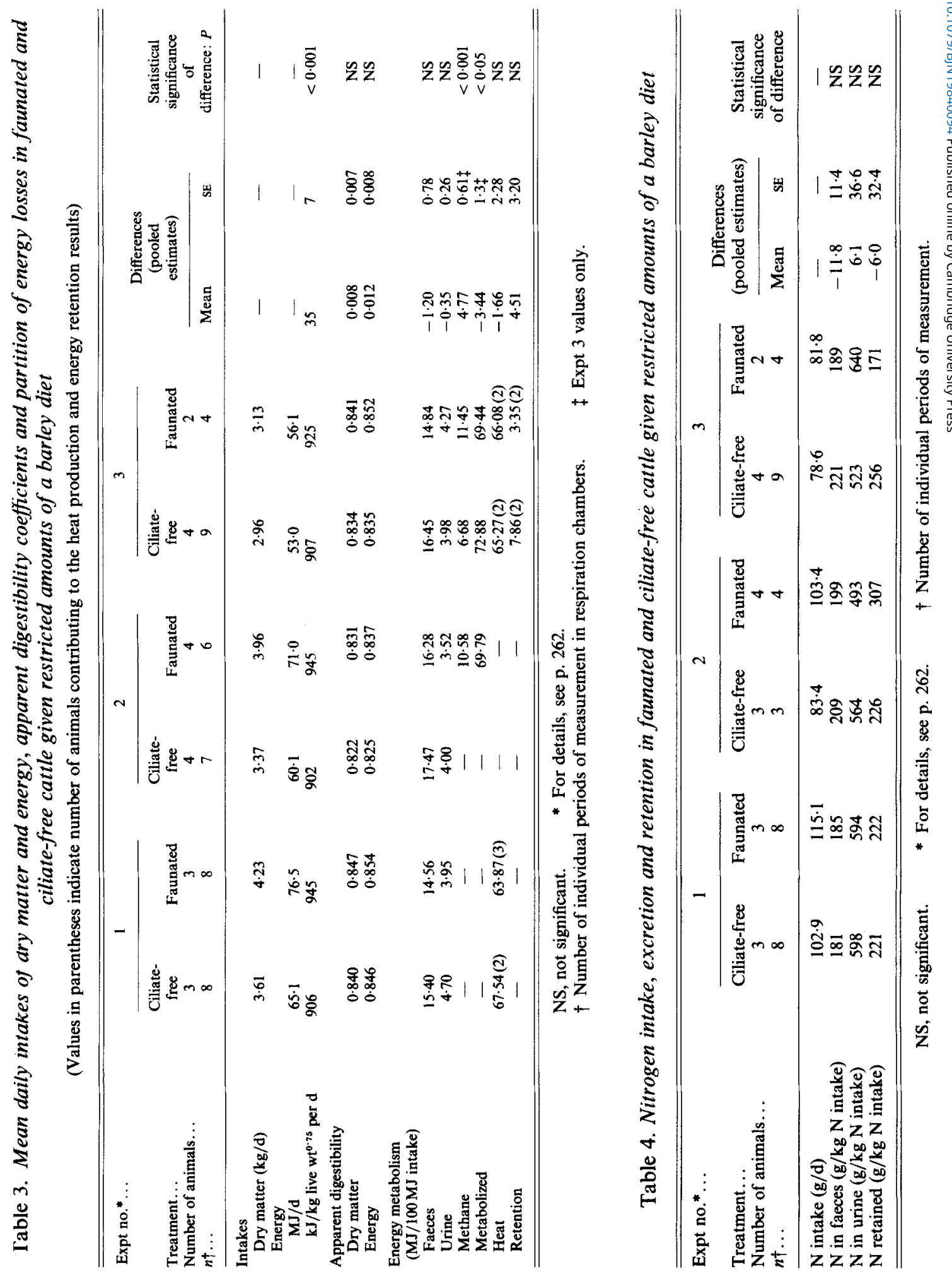


ranged from 1.90 to $2 \cdot 18 \mathrm{~g} / \mathrm{MJ} \mathrm{ME}$ and did not differ significantly between groups. Similarly no significant differences could be detected between treatments in the proportions of $\mathrm{N}$ excreted in faeces or urine or retained in body tissue. The mean retention of $\mathrm{N}(\mathrm{g} / \mathrm{d})$ over all treatment groups was $22 \cdot 9$ (SE 1.7).

\section{DISCUSSION}

\section{Methane production and the role of the ciliate protozoa}

It is evident from these results that the presence of large populations of ciliate protozoa in the rumen results in a marked increase in the energy lost as $\mathrm{CH}_{4}$ in cattle given an all-barley diet. The mean difference in $\mathrm{CH}_{4}$ production between faunated animals and similar animals maintained free of protozoa was about $4.8 \mathrm{MJ} / 100 \mathrm{MJ}$ energy intake, or approximately 75-100 litres $\mathrm{CH}_{4} / \mathrm{d}$, depending on intake. The $\mathrm{CH}_{4}$ values recorded for faunated animals in these experiments not only represented a $1 \cdot 70$-fold increase over the ciliate-free values but appeared also to be some of the highest ever reported. Thus, in the ten sets of 3-4 d observations for which reliable values for faunated animals were available (Expts $2 b$ and 3 ) the energy lost as $\mathrm{CH}_{4}$ ranged from 9.49 to $12.88 \mathrm{MJ} / 100 \mathrm{MJ}$ intake whereas Blaxter \& Clapperton (1965) reported a range of 6.2-10.8 MJ/100 MJ intake in a study involving 391 individual 4-5 d periods of measurement with sheep given diets varying in composition from all-roughage to all-concentrate. These authors showed that $\mathrm{CH}_{4}$ production in sheep was related both to the digestibility of dietary energy (D) and the level of feeding (L) (Blaxter \& Clapperton, 1965) but the prediction equations they derived for the estimation of $\mathrm{CH}_{4}$ from $\mathrm{D}$ and $\mathrm{L}$ cannot be applied to the current work since $\mathrm{D}$ did not differ between treatments and the small increase in estimated $L$ (from 1.40 to 1.49 ) resulting from the change in metabolizability of the diet would have little effect on the predicted $\mathrm{CH}_{4}$ value. Similarly, earlier prediction equations relating $\mathrm{CH}_{4}$ formation to the intakes of DM (Kriss, 1930; Kleiber et al. 1945; Axelsson, 1949) or of digestible or soluble carbohydrate (Bratzler \& Forbes, 1940; Swift et al. 1948; Axelsson, 1949) are of no relevance here since the intakes of these dietary components also remained virtually constant across treatment groups. A further anomaly in the present study was the pattern of $\mathrm{CH}_{4}$ production throughout the day (Fig. 1) where both faunated and ciliate-free animals failed to exhibit the large peaks of production usually seen immediately after feeding (Blaxter, 1967) and which are assumed to be associated with the fermentation of readily available carbohydrate (Clapperton \& Czerkawski, 1967). Thus both the pattern and the levels of $\mathrm{CH}_{4}$ production in the present work appear to be different from those normally encountered and obviously cannot be explained by reference to the composition or quantity of the diet.

There is now ample evidence that $\mathrm{CH}_{4}$ in the rumen is formed from $\mathrm{H}_{2}$ by the action of methanogenic bacteria, mainly Methanobacterium ruminantium (Hungate, 1966, 1967), and that the $\mathrm{H}_{2}$ required arises principally in the formation of acetic and butyric acids (Wolin, 1960). Propionic acid formation on the other hand requires a net uptake of $\mathrm{H}_{2}$ and the quantity of $\mathrm{CH}_{4}$ produced depends ultimately on the relative rates of formation of the three major rumen acids (Wolin, 1960; Hungate, 1966). However, as these acids are produced in varying proportions by a great number of different bacterial and protozoal species in the rumen it is not usually possible to identify which organisms are responsible for the production of the excess $\mathrm{H}_{2}$ contributing to $\mathrm{CH}_{4}$ formation.

One possible exception to this generalization would be the situation in which the rumen microbial population consisted of a limited number of organisms. In the present work a large proportion of the rumen bacterial population under ciliate-free conditions consisted of Bacteroides spp. and this organism persisted as the predominant bacterial species even after the introduction of the protozoal populations. Similarly, once established, the ciliate 
populations consisted only of Epidinium spp., Eremoplastron spp. and Entodinium spp. Both populations therefore would be considered 'limited' in terms of the number of microbial species present, and concurrent in vitro studies (B. H. Howard and P. N. Hobson, unpublished results) indicated that the bacterial and protozoal components of the populations produced quite different proportions of VFA. These findings confirmed earlier observations associating Bacteroides spp. with the production of propionic acid (Hungate, 1966) and rumen ciliates with the production of mainly acetic and butyric acids (Abou Akkada \& Howard, 1960; Gutierrez \& Davis, 1962). Thus it seems likely that the ciliate populations in the present work were responsible for the shift in rumen VFA proportions towards acetic and butyric acids and hence for the additional amounts of $\mathrm{H}_{2}$ arising from the fermentation. Recent reports suggest that the transfer of this $\mathrm{H}_{2}$ to the rumen methanogens for $\mathrm{CH}_{4}$ formation is facilitated by an ectosymbiotic attachment of these bacteria to the ciliate cell surfaces (Vogels et al. 1980; Stumm et al. 1982).

\section{Relationships between rumen $\mathrm{VFA}$ and $\mathrm{CH}_{4}$ formation}

Each of the three major VFA, either alone or in combination, showed highly significant linear relationships with measured $\mathrm{CH}_{4}$ production. As outlined previously, stoichiometric theory suggests that propionic acid formation competes directly with $\mathrm{CH}_{4}$ formation for the available $\mathrm{H}_{2}$ and this is confirmed by the close inverse relationship which existed between propionic acid proportions and the quantity of $\mathrm{CH}_{4}$ produced (Fig. 2). As indicated earlier, stoichiometric estimates of $\mathrm{CH}_{4}$ production tend to be maximum values since they assume that all 'excess' $\mathrm{H}_{2}$ produced in fermentation is converted to $\mathrm{CH}_{4}$. Statistical tests on the observed relationships between propionic acid on the one hand and either 'measured' or 'calculated' $\mathrm{CH}_{4}$ values on the other (Table 2) showed that the regression coefficients did not differ significantly but that the stoichiometric estimates exceeded the measured $\mathrm{CH}_{4}$ values over the whole range of propionic acid proportions $(P<0.05)$. The extent of overestimation did not differ between the faunated and ciliate-free treatments and was on average 0.696 (SE 0.284) $\mathrm{MJ} \mathrm{CH} / 100 \mathrm{MJ}$ intake; compared with the mean measured $\mathrm{CH}_{4}$ level of $8.78 \mathrm{MJ} / 100 \mathrm{MJ}$ intake this indicates that $\mathrm{CH}_{4}$ and propionate together accounted for 0.93 of the $\mathrm{H}_{2}$ arising in the fermentation as estimated stoichiometrically. The $\mathrm{H}_{2}$ unaccounted for presumably represents that involved in the minor hydrogenation reactions of the rumen (Czerkawski, 1972), incorporated into bacterial and protozoal proteins (Czerkawski, 1975) or attributable to any dietary hexose which failed to be fermented in the rumen.

\section{Fermentation of dietary carbohydrate}

Other indices of fermentation can obviously be calculated from the observed intakes of digestible carbohydrate and the measured $\mathrm{CH}_{4}$ production and VFA proportions using the fermentation balance approach outlined by Ørskov et al. (1968). Values calculated in this way from the results obtained in Expts $2 b$ and 3 are given in Table 5 and show that the efficiency of conversion of dietary hexose to VFA was significantly higher for the ciliate-free than for the faunated animals $(P<0.01)$. In contrast to earlier findings (Whitelaw $e t$ al. 1970 ) however, the estimated daily production of VFA did not differ significantly between treatment groups. Of particular interest is the 'extent of fermentation' of dietary carbohydrate which was calculated to be 0.90 and 0.78 for faunated and ciliate-free groups respectively. These values did not differ significantly between treatment groups but are obviously very much higher than those reported by Ørskov et al. (1968), which ranged from 0.71 to 0.47 in progressing from a value of 100:0 to 20:80 for roughage: concentrate ratio in the diet. The high proportion of ground maize in their concentrate mixture and the high levels of feeding adopted could have resulted in significant amounts of starch escaping rumen fermentation (Karr et al. 1966; Wright et al. 1966) and might explain the reduction in the extent of 
Methane formation in cattle

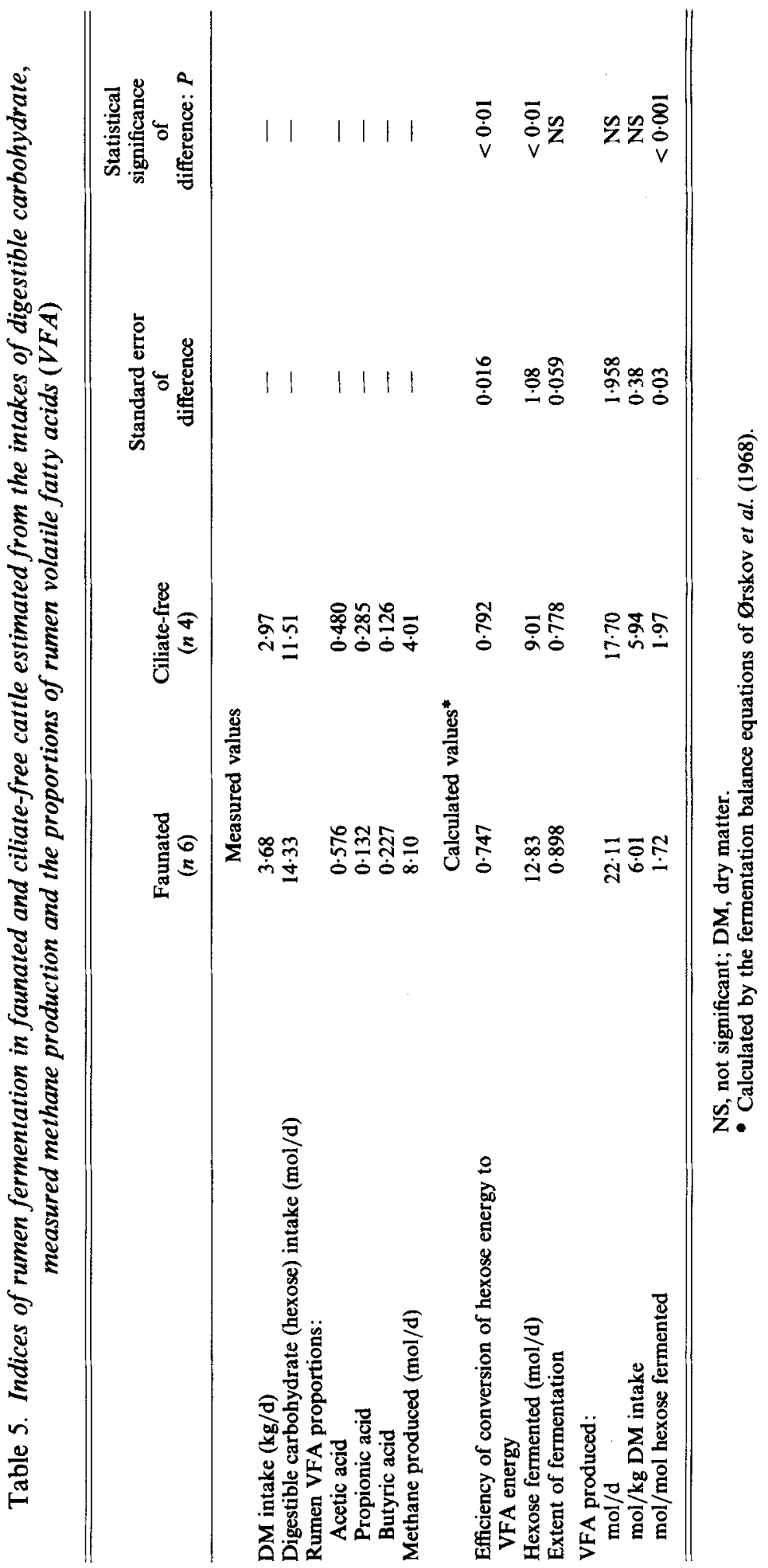


fermentation as the proportion of concentrate in the diet was increased (Ørskov et al. 1968). Barley grain, as used in the present study, is known to be extensively fermented in the rumen and only limited quantities of dietary starch, approximately 0.05 of intake, have been observed at the duodenum of steers on this feeding regimen (Topps et al. 1968). Allowing that a further $0 \cdot 10-0 \cdot 12$ of the substrate fermented might be represented by the microbial matter synthesized in the rumen (Hungate, 1966), the overall mean value for the extent of fermentation, 0.85 (SE 0.03), would appear to be a realistic estimate.

The conclusion to be drawn from the present study is that the presence of ciliate protoza in the rumen on this particular dietary regimen results in major changes in the proportions of VFA in the rumen and this, in turn, gives rise to a substantial increase in $\mathrm{CH}_{4}$ formation. Since only minor differences exist between faunated and ciliate-free animals in the proportional losses of energy in faeces and urine the differences in $\mathrm{CH}_{4}$ energy losses are reflected in significant and almost equivalent differences between treatments in the ME available for production. Animals in the two groups showed no significant difference in heat production and it can be postulated that the observed changes in ME would give rise to corresponding differences in energy retention between the two treatments: differences in energy retention of this magnitude were observed in the present work but failed to reach significance.

It is important to note that these changes in rumen VFA proportions and associated measurements relate only to animals fed on barley-based concentrates. Only minor changes in VFA pattern have been noted between faunated and ciliate-free animals given traditional roughage or roughage-concentrate diets, probably because the ciliate populations seen on those more conventional diets tend to be small relative to those encountered on the barley diet. In the only study in which $\mathrm{CH}_{4}$ production has been measured in faunated and ciliate-free sheep given traditional diets no significant difference was detected between treatments (Eadie \& Gill, 1971).

The authors are indebted to Dr R. N. B. Kay for performing the surgery on the experimental animals and to $\mathrm{Mr}$ I. McDonald for statistical analysis. They are grateful also to the staff of the Energy Metabolism Department of this Institute for the operation of the respiration chambers and to Mr R. S. Reid for skilled technical assistance.

\section{REFERENCES}

Abou Akkada, A. R. \& Howard, B. H. (1960). Biochemical Journal 76, 445-451.

Axelsson, J. (1949). Kungliga Lantbrukhogskolans Annaler 16, 404-419.

Blaxter, K. L. (1967). The Energy Metabolism of Ruminants, p. 199. London: Hutchinson.

Blaxter, K. L., Brockway, J. M. \& Boyne, A. W. (1972). Quarterly Journal of Experimental Physiology 57, 60-72.

Blaxter, K. L. \& Clapperton, J. L. (1965). British Journal of Nutrition 19, 511-522.

Bratzler, J. W. \& Forbes, E. B. (1940). Journal of Nutrition 19, 611-613.

Brockway, J. M., Boyne, A. W. \& Gordon, J. G. (1971). Journal of Applied Physiology 31, $296-297$.

Brouwer, E. (1965). In Energy Metabolism: Proceedings of 3rd Symposium on Energy Metabolism, Troon. EAAP Publication no. 11, p. 441 [K. L. Blaxter, editor]. London: Academic Press.

Clapperton, J. L. \& Czerkawski, J. W. (1967). Proceedings of the Nutrition Society 26, XXI.

Czerkawski, J. W. (1969). World Review of Nutrition and Dietetics 11, 240-278.

Czerkawski, J. W. (1972). Proceedings of the Nutrition Society 31, 141-146.

Czerkawski, J. W. (1975). In Tracer Studies on Non-Protein Nitrogen for Ruminants, vol. 2, pp. 55-63. Vienna: International Atomic Energy Authority.

Davidson, J., Mathieson, J. \& Boyne, A. W. (1970). Analyst 95, 181-193.

Eadie, J. M. (1967). Journal of General Microbiology 49, 175-194.

Eadie, J. M. \& Gill, J. C. (1971). British Journal of Nutrition 26, $155-167$.

Eadie, J. M., Hyldgaard-Jensen, J., Mann, S. O., Reid, R. S. \& Whitelaw, F. G. (1970). British Journal of Nutrition 24, $157-177$.

Eadie, J. M. \& Mann, S. O. (1970). In Physiology of Digestion and Metabolism in the Ruminant, pp. 335-347

[A. T. Phillipson, editor]. Newcastle upon Tyne: Oriel Press. 
Eadie, J. M. \& Oxford, A. E. (1955). Journal of General Microbiology 12, 298-310.

Fell, B. F., Kay, M., Whitelaw, F. G. \& Boyne, R. (1968). Research in Veterinary Science 9, 458-466.

Gutierrez, J. \& Davis, R. E. (1962). Applied Microbiology 10, 305-308.

Hungate, R. E. (1966). The Rumen and Its Microbes. New York and London: Academic Press.

Hungate, R. E. (1967). Archiv für Mikrobiologie 59, 158-164.

Karr, U. R., Little, C. O. \& Mitchell, G. E. Jr (1966). Journal of Animal Science 25, 652-654.

Kleiber, M., Regan, W. M. \& Mead, S. W. (1945). Hilgardia 16, 511-571.

Kriss, M. (1930). Journal of Agricultural Research 40, 283-295.

Kurihara, Y., Eadie, J. M., Hobson, P. N. \& Mann, S. O. (1968). Journal of General Microbiology 51, $267-288$.

McKenzie, J. D. \& Kay, R. N. B. (1968). Journal of Science and Technology 14, 15-16.

Ørskov, E. R., Flatt, W. P. \& Moe, P. W. (1968). Journal of Dairy Science 51, 1429-1435.

Preston, T. R. (1963). Veterinary Record 75, 1399-1402.

Pullar, J. D. (1969). In International Encyclopaedia of Food and Nutrition vol. 17, Nutrition of Animals of Agricultural Importance, pp. 471-490 [D. P. Cuthbertson, editor]. Oxford: Pergamon Press.

Stumm, C. K., Guzen, H. J. \& Vogels, G. D. (1982). British Journal of Nutrition 47, 95-99.

Swift, R. W., Bratzler, J. W., James, W. H., Tillman, A. D. \& Meek, D. C. (1948). Journal of Animal Science 7, 475-485.

Topps, J. H., Kay, R. N. B., Goodall, E. D., Whitelaw, F. G. \& Reid, R. S. (1968). British Journal of Nutrition 22, 281-290.

Vogels, G. D., Hoppe, W. F. \& Stumm, C. K. (1980). Applied and Environmental Microbiology 40, 608-612.

Webster, A. J. F., Brockway, J. M. \& Smith, J. S. (1974). Animal Production 19, 127-139.

Whitelaw, F. G., Eadie, J. M., Bruce, L. A. \& Shand, W. J. (1983). Proceedings of the Nutrition Society 42, 158 A.

Whitelaw, F. G., Eadie, J. M., Mann, S. O. \& Reid, R. S. (1972). British Journal of Nutrition 27, $425-437$.

Whitelaw, F. G., Hyldgaard-Jensen, J., Reid, R. S. \& Kay, M. G. (1970). British Journal of Nutrition 24, $179-195$.

Wolin, M. J. (1960). Journal of Dairy Science 43, 1452-1459.

Wright, P. L., Grainger, R. B. \& Marco, G. J. (1966). Journal of Nutrition 89, 241-246. 